\title{
Developing high performance asphalt mixtures with considerable amounts of recycled asphalt with a new chemical bitumen additive
}

\author{
N. Carreño \& M. Oeser \\ Institute of Highway Engineering, RWTH Aachen University, Aachen, NRW, Germany \\ M. Zeilinger \& O. Fleischel \\ BASF SE, Ludwigshafen, RLP, Germany
}

\begin{abstract}
Due to the increase of heavy traffic worldwide, many roads are being repaved to be able to support this demand. This generates an ever-growing amount of reclaimed material which is increasingly challenging to recycle due to bitumen aging. A new type of reactive chemical additive (B2Last $\left.{ }^{\circledR}\right)$, tested at the laboratory of the Institute of Highway Engineering of the RWTH Aachen University, has shown to increase the asphalt performance by creating an elastic network within the bitumen. The additive reacts with the functional groups within the neat and oxidized bitumen producing a good performing bitumen in mixtures with or without reclaimed asphalt. The additive has also shown to increase the workability of the asphalt mixtures, as well as the performance against rutting and fatigue, without disrupting the low temperature behavior. By using softer base bitumen, like a neat 70/100 bitumen, the modified bitumen is able to perform well at very low temperatures, and also at very high ones. This is seen on laboratory bitumen and asphalt tests, as well as on mixture samples taken from the construction of a real-life track close to Munich. There, a 200-meter-long binder layer was built with 50\% reclaimed asphalt in June 2019. With a small amount of additive mixed with a neat $70 / 100$ bitumen, the workability on site of the mixture was improved, and the performance was on the same level as the reference track, where an SBS modified bitumen was employed.
\end{abstract}

Keywords: Modified bitumen, performance testing, reclaimed asphalt, asphalt recycling

\section{INTRODUCTION}

The increase in traffic and the changing climatic conditions are bringing flexible pavements to its limits. Many roads are being partially or completely repaved to be able to withstand this increase in demand. As a result, more and more reclaimed asphalt material is generated, which is increasingly challenging to recycle due to bitumen oxidative aging. Mixtures with high ratios of recycled asphalt are usually avoided, since they are difficult to re-process (due to high viscosity) and can compromise asphalt performance, specially the low temperature behavior (Krishna Swamy et al. 2011). This creates some challenges for the industry, since the production of reclaimed asphalt increases year by year.

The purpose of this paper is to present the findings on the use of a novel chemically modified bitumen which has been employed during the construction of real test track. The additive is an isocyanate-based modifier developed by BASF. This additive reacts chemically with the functional groups of the bitumen, creating a cross-linked polymeric network between the 
polar fractions of the bitumen (mainly asphaltenes, resins and even aromatics), corresponding mainly to the n-heptane insoluble fraction of bitumen (see Figure 1a). Specifically, the reactive groups contained in the polymeric chains of the polyurethane-precursor react with the nucleophilic groups within the bitumen, creating a flexible network made of urethane functionalities, but not limited to those ones. This network can increase the elastic behavior of the bitumen, impacting the high temperature performance and limiting its thermal susceptibility.

Oxidative aging of bitumen during the service life of a pavement generates more functional groups in the binder (Lesueur 2009). Therefore, when using this isocyanate-based additive in mixtures with reclaimed asphalt, the additive has more anchoring points to react with, as it can be seen in Figure 1b. This is believed to improve the homogenization and the compatibilization of both phases into the asphalt mix with high amounts of reclaimed asphalt and to ease the workability of the asphalt mixture during construction. Upon addition of the additive to neat bitumen and subsequent mixing with aggregates, a quick reaction leads to a full immobilization of the additive whereas not all isocyanate functionalities are consumed. During the mixing process with aggregates, the additive reacts with anchoring points of reclaimed asphalt and further ones which are generated in situ by oxidation. Once the crosslinking reaction is completed, which is believed to happen at the last phase of the pavement construction (generation of further anchoring points at laydown), the modified bitumen's viscosity increases and has a similar behavior to polymer modified bitumen. This type of modification does not require any swelling time nor high blending energy (e.g. high shear mixer) prior to the asphalt mixture production. The results of the preliminary studies can be found in (Carreño et al. 2020).

a)

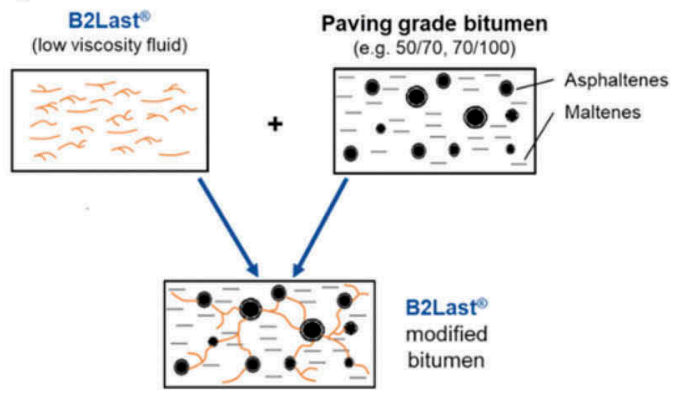

b)

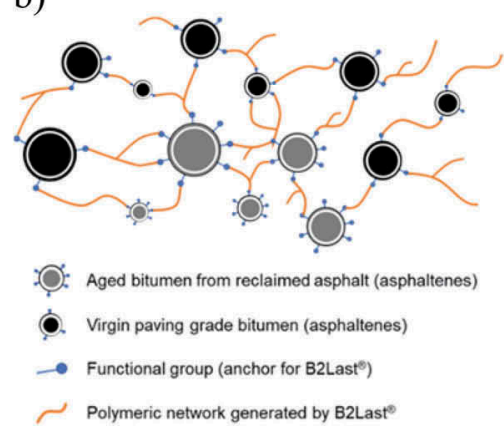

Figure 1. Working principle of chemical modification with B2Last ${ }^{\circledR}$ (www.b2last.com).

Isocyanate-based bitumen modification is not completely new. State of the art on similar use of this modification type has been well described in literature. (Cuadri et al. 2013; Cuadri et al. 2015; Navarro et al. 2007) have all used reactive chemical addition but in a different manner, due to the versatility this type of chemical allows. Prior to the blending, different organic polyols have been used to previously deactivate the isocyanate to form a polyurethane network within the bitumen. Enough free - NCO groups are left unreacted to react during a second step with the functional groups of the bitumen.

\section{TEST SECTION}

In this publication, the results of a test track construction with a total length of 200 meters are presented. The construction took place in June 2019 in the outskirts of Munich (A-96), where 
the binder layer was paved using a neat $70 / 100$ bitumen, modified with $1.7 \%$ of the isocyanate-based additive by weight referred to the total bitumen content (neat and reclaimed). The test track was built in a motorway service area (Figure 2), using Hot Mix Asphalt (HMA). For comparison, a control track on the same station was chosen since it is supposed to be submitted to similar traffic load and temperatures. Asphalt mixture samples were taken from both test and control track. The base layer of the control track was made from a 25/55-55 RC bitumen, which is an elastomeric polymer modified bitumen.

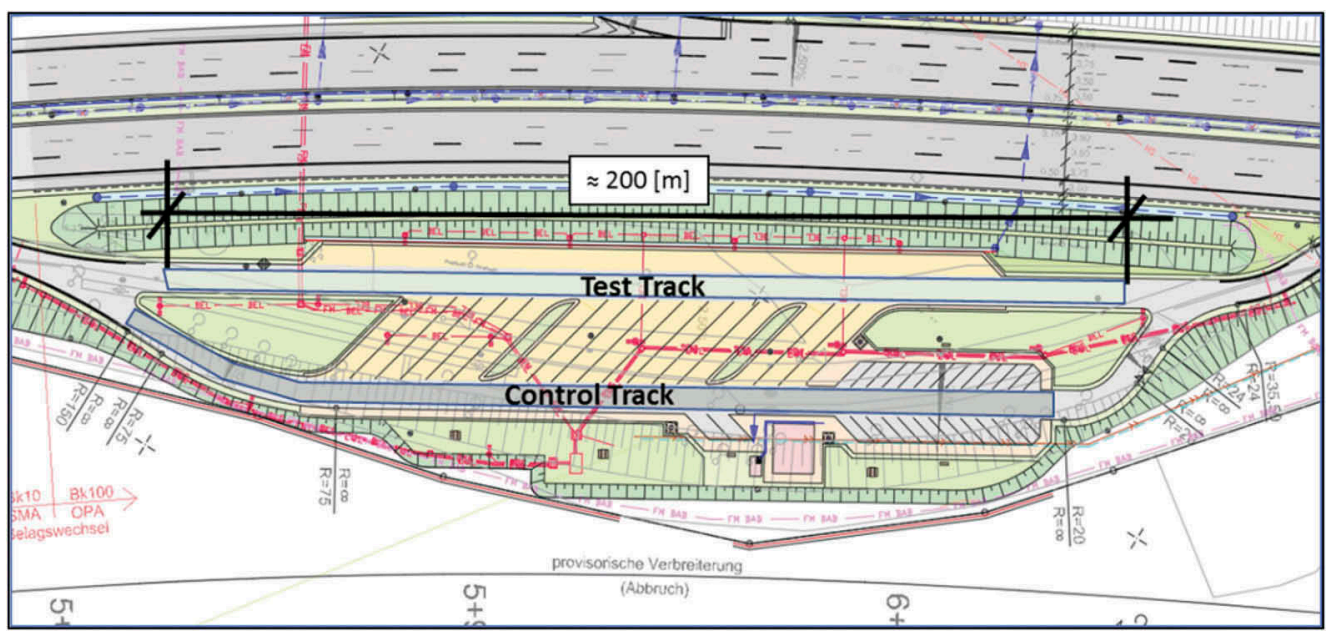

Figure 2. Sketch of test track and control track.

In this investigation, the similar methodology that has been applied throughout the joint research project was applied. First, the modification was analyzed through conventional and rheological tests. Afterwards, the relevant asphalt tests were performed on asphalt samples produced in the laboratory with mixture taken at the construction site. Additionally, longitudinal and cross section profile measurements were planned for both test and control tracks with a S.T.I.E.R. measuring vehicle. The first measurement took place in June 2020, whereas the second one will be investigated 6 months later. Since a comparison is not yet possible, these results haven't been included in this publication.

\section{MATERIALS}

\subsection{Isocyanate-based additive}

The additive used in the investigation is an isocyanate-based additive, called B2Last ${ }^{\circledR}$, specifically designed for bitumen modification, developed by BASF. It is a black liquid with a low viscosity $\left(210 \mathrm{mPas}\right.$ at $\left.25^{\circ} \mathrm{C}\right)$. As mentioned previously, this additive reacts chemically with the polar fractions of the bitumen creating a cross-linked network among the asphaltenes, resins and even aromatics fractions. This reaction occurs as soon as the additive comes into contact with the bitumen. Knowing that the chemical value of aged bitumen binder from reclaimed asphalt pavement is higher than neat bitumen, meaning the polar phase bears more reactive groups, such additive will react even in a better way with aged bitumen. For the construction, and in this investigation, a 70/100 penetration grade bitumen was used as base bitumen to be modified with the novel additive. 


\subsection{Asphalt mixture and laboratory samples for bitumen and asphalt tests}

The focus of this investigation was set on the binder layer. To contrast the results, samples of mixture were taken from a reference track that is expected to be submitted to the same amount of traffic load. The reference (or control) track was paved with a 25/55-55 RC bitumen. This is an elastomer modified bitumen with a needle penetration between 25 and 55 $\mathrm{dmm}$ and a softening point above $55{ }^{\circ} \mathrm{C}$. The $\mathrm{RC}$ at the end usually stands for a slightly higher polymer content, but no information on the effective amount of SBS was available. All bitumen tests were performed on laboratory extracted material.

The binder layer of both test and control tracks was an AC 22 B S (dense graded asphalt concrete mixture with a maximum aggregate size of $22 \mathrm{~mm}$ ), both with $50 \%$ of reclaimed asphalt. The mixture properties of the mixtures can be seen in Table 1. These values are from asphalt mixtures gathered at the construction site during paving operations.

Table 1. Main Properties of both asphalt mixtures.

\begin{tabular}{|c|c|c|c|}
\hline Properties & & B2 Last ${ }^{\circledR}$ & Reference \\
\hline \multirow{3}{*}{ Minerals } & & Limestone filler & Limestone filler \\
\hline & & Crushed Gravel & Crushed Gravel \\
\hline & & $\begin{array}{l}50 \% \text { Reclaimed Asphalt } \\
\text { (diverse Aggregates) }\end{array}$ & $\begin{array}{l}50 \% \text { Reclaimed Asphalt } \\
\text { (diverse Aggregates) }\end{array}$ \\
\hline Bitumen & & $70 / 100+1,7 \%$ B2Last & 25/55-55 RC \\
\hline Bitumen Content & [wt. \%] & 4,4 & 4,2 \\
\hline Air Void Content & [vol.\%] & 5,0 & 4,7 \\
\hline
\end{tabular}

As required in Germany, as soon as a new element is incorporated to a mixture, a suitability test must be performed. As starting point, the standard recipe for the PmB was taken. Only small adaptations were made to obtain a satisfactory air void content, so both granulometric curves were very similar.

For bitumen tests, bitumen was extracted using an infraTest Asphalt Analyzer following the corresponding German standards. For asphalt testing, samples were sawed and drilled from roller segment compactor plates, depending on the geometries required for the different tests following the German standards.

\section{METHODS}

\subsection{Bitumen modification at asphalt mixing plant}

In order to produce isocyanate-based modified asphalt mixture at the mixing plant, two small adjustments had to be operated at the plant: i) a pump including piping elements was installed to dose the additive into the bitumen weighing chamber; ii) a propeller stirrer was installed in the weighing chamber to shortly homogenize the additive into bitumen before the whole liquid phase is pumped to the mixer. The modification process didn't affect the normal production operations or temperatures (approximately $170{ }^{\circ} \mathrm{C}$ during production and $165{ }^{\circ} \mathrm{C}$ during construction) of the mixing plant, allowing it to operate effectively. One part of the reaction occurs when the additive comes in contact with the bitumen and subsequently with aggregates during the mixing process (additive immobilization). The other part takes place during transport and road construction (completing the crosslinking reaction). Due to the process setup, the only way to study the modification is through bitumen extraction after asphalt mix production. 


\subsection{Bitumen testing}

To study the effect of the isocyanate-based additive on bitumen, different tests were performed. Aside from the standard tests such as softening point and elastic recovery tests, different rheological tests were investigated. To characterize the high temperature behavior of the binder, the Multiple Stress Creep Recovery test (MSCR) and the Bitumen-Typisierung-Schnell-Verfahren (BTSV, in English: Binder-Fast-Characterization-Test) were done with the Dynamic Shear Rheometer (Anton Paar MCR 702 Multidrive). The MSCR has proven to correlate well with the rutting performance of asphalt mixtures (D'Angelo 2009; Zhang et al. 2015) and can indicate the behavior of a binder at high temperatures. This test is made with the $25 \mathrm{~mm}$ plateplate system at 60 degrees ( $1 \mathrm{~mm}$ gap). The sample is loaded with a constant shear stress of 3,2 $\mathrm{kPa}$ for one second and then left to relax for nine seconds. The latter is repeated ten times. The recovery and permanent deformation after each cycle is recorded and used to obtain the average percent recovery $(\mathrm{R})$ and the non-recoverable creep compliance $\left(\mathrm{J}_{\mathrm{nr}}\right)$.

The BTSV method, on the other hand, is a novel method that allows to determine the upper limit of the elastoplastic range via a rheology method (Alisov et al. 2020). This test is performed by applying an oscillatory shear stress of $500 \mathrm{~Pa}$ at a frequency of $1,59 \mathrm{~Hz}$, while the temperature is raised from $20{ }^{\circ} \mathrm{C}$ to $90{ }^{\circ} \mathrm{C}$ at a rate of $1,2 \mathrm{~K} / \mathrm{min}$. Using the $25 \mathrm{~mm}$ plate-plate system, the complex shear modulus and phase angle are obtained for the entire temperature range. From this test, two key parameters are obtained: $T_{B T S V}$ (Temperature at a complex shear modulus of $15 \mathrm{kPa}$ ) and the $\delta_{\mathrm{BTSV}}$ (Phase angle at $\mathrm{T}_{\mathrm{BTSV}}$ ). The first parameter is meant to correct the softening point for polymer modified bitumen, since the softening point is able to characterize only neat bitumen, whereas the phase angle is meant to help quantify the modification level of bitumen. This test is planned to replace the softening point in Germany in a near future.

Additionally, the bending beam rheometer was used to perform three-point bending tests at two different temperatures in order to determine the higher temperature between the one at which the m-value reaches 0,300 (iso-m-value temperature) and the one at which the stiffness reaches $300 \mathrm{MPa}$ (iso-modulus temperature). The low temperature continuous grade was determined by using the ASTM D7643 standard. Following the Superpave binder specification and (Bahia and Anderson 1995), the values measured with the BBR represent properties at a pavement design temperature $10^{\circ} \mathrm{C}$ lower.

\subsection{Asphalt testing}

In this investigation, the rutting and low temperature behavior were the main performances that were evaluated. The main attributes of the binder layer are to stay stable against permanent deformation, and have a good low temperature behavior, to not crack in the winter. The rutting behavior was studied with two tests: the wheel tracking test and the uniaxial cyclic compression test. Both of them are standards tests used in Germany to study the rutting susceptibility of asphalt layers, since they are very practical and correlate well with the rutting performance of roads (Karcher 2012; Radhakrishnan et al. 2019). Both tests were performed following the respective German standard. The wheel tracking test was performed by loading simultaneously two $80 \mathrm{~mm}$ thick roller compactor plates $(320 \mathrm{~mm}$ x $260 \mathrm{~mm})$ for 20.000 cycles using a rubber wheel $(700 \mathrm{~N})$ at $60{ }^{\circ} \mathrm{C}$. The uniaxial cyclic compression test consisted in loading cylindrical $60 \mathrm{~mm}$ thick specimens drilled from roller compactor plates for 10.000 cycles at $10 \mathrm{~Hz}$ with a Haversine load (load impulse $0.2 \mathrm{~s}$ long with afterwards a break $1.5 \mathrm{~s}$ long) and at $50{ }^{\circ} \mathrm{C}$.

To study the low temperature behavior, two tests were carried out: the thermal stress restrained specimen test (TSRST) and the uniaxial tensile strength test (UTST). Both tests were performed following the respective German standard as well. The first test consists on holding the length of a prismatic asphalt beam constant while lowering the temperature from $20{ }^{\circ} \mathrm{C}$ to $-40{ }^{\circ} \mathrm{C}$ at a rate of $10 \mathrm{~K} / \mathrm{hr}$. Since the asphalt specimen are not able to contract, cryogenic stresses build up within the sample, thus producing eventually a temperature crack. In the UTST, prismatic specimens are pulled apart at a strain rate of $0.625 \% / \mathrm{min}$ and at 
different temperatures. In this case, due to availability of asphalt mixture, this test was performed only at $-10{ }^{\circ} \mathrm{C}$ for both materials.

\section{RESULTS AND DISCUSSION}

\subsection{Bitumen results}

All bitumen test results can be found in Table 2. On the one hand, one can see that both bitumen have a similar softening point. Due to the different nature of the modification with the isocyanate-based modifier compared to a classical polymer modification (e.g. SBS), the elastic recovery test is not applicable. This test is thought only to identify elastomeric polymers in polymer modified bitumen and does not represent in any way bitumen performance. The deformations to which the material is submitted do not represent real pavement deformations. Many federal agencies in Europe still require this test for all polymer modified bitumen which makes the use of other additives rather difficult. The cross-linked network formed by the polyurethane-precursor-based additive enhances the elasticity of bitumen at small deformations, similar to the ones that a flexible pavement is submitted to, but not at large displacements as is intended with the elastic recovery test.

In the BTSV test, a clear difference between softening point and the $\mathrm{T}_{\mathrm{BTSV}}$ can be seen, although the difference between both materials remains fairly the same. The $\delta_{\mathrm{BTSV}}$, shows that the polymer modified reference material is more elastic and thus slightly higher modified than the isocyanate-based modified bitumen. With regards to the MSCR test, the results go in hand with what was observed in the results of the BTSV test. Due to the nature of the modification, the percent recovery of the reference materials is higher than the B2Last ${ }^{\circledR}$-modified bitumen, while the non-recoverable creep compliance is slightly lower. With regards to the high temperature performance it can be stated that both materials are on a very similar level.

Table 2. Bitumen test results.

\begin{tabular}{|c|c|c|c|c|}
\hline \multicolumn{2}{|c|}{ Bitumen Tests } & Unit & $70 / 100+1.7 \%$ B2Last ${ }^{\circledR}$ & $25 / 55-55 \mathrm{RC}$ \\
\hline \multicolumn{2}{|c|}{ Softening Point } & {$\left[{ }^{\circ} \mathrm{C}\right]$} & 65.6 & 67.0 \\
\hline \multicolumn{2}{|c|}{ Elastic Recovery } & {$[\%]$} & not determined & 47 \\
\hline \multirow{2}{*}{ BTSV } & $\mathrm{T}_{\mathrm{BTSV}}$ & {$\left[{ }^{\circ} \mathrm{C}\right]$} & 60.3 & 62.0 \\
\hline & $\delta_{\mathrm{BTSV}}$ & {$\left[{ }^{\circ}\right]$} & 72.0 & 69.8 \\
\hline \multirow{3}{*}{$\begin{array}{l}\text { MSCR } \\
\text { BBR }\end{array}$} & Recovery & {$[\%]$} & 16.5 & 35.9 \\
\hline & Jnr & {$[1 / \mathrm{kPa}]$} & 0.530 & 0.284 \\
\hline & $\mathrm{T}^{\circ}(\mathrm{m}$-value $=0.300$ or $\mathrm{S}=300 \mathrm{MPa})$ & {$\left[{ }^{\circ} \mathrm{C}\right]$} & -23.5 & -22.4 \\
\hline
\end{tabular}

With respect to the low-temperature behavior, it can be concluded that both materials showed a very similar behavior as well. The three-point bending beam results reflected that the highest temperature between the iso-m-value and the iso-modulus temperatures of both materials is $1.1 \mathrm{~K}$ apart from each other, being the isocyanate-based modified bitumen the material with the better low-temperature value. This is to be expected since, depending on the base (neat) bitumen and the modification method, the influence of the B2Last ${ }^{\circledR}$ additive should be negligible. Therefore, by modifying a soft binder, it is possible to have a good low temperature behavior, and improve the high temperature behavior, thus extending the useful temperature interval of the bitumen. Additionally, by using a softer binder, the workability can be improved, since the viscosity is then lower. In summary, the bitumen tests results demonstrate that the novel additive can deliver a comparable performance. 


\section{2}

Asphalt results

\subsubsection{Rutting stability}

The results of the wheel tracking test (Figure 3a) show a very similar rutting performance for both modifications. None of the curves have an inflection point, and the average rut depth at the end of the 20.000 cycles was $3.35 \mathrm{~mm}$ for the B2Last ${ }^{\circledR}$ modified base layer, while the polymer modified base layer had a higher average rut depth of $3.67 \mathrm{~mm}$. This correlates with what was seen on a bitumen level and again indicates that both materials perform similarly with regard to stability against permanent deformation.

The UCCT (Figure 3b) demonstrates a similar rutting behavior as well. In this case, the polymer modified variant has a slightly higher performance than the isocyanate-based modified variant. None of the samples presented an inflection point and the main difference lies in the strain and strain-rate at the end of the 10.000 cycles. The reference material had a strain on average of $36,5 \%$, while the novel additive had a strain on average of $40,8 \%$. The strain rate after the 10.000 cycles are $7,2 \%{ }^{*} 10^{-4} / \mathrm{n}$ and $12,7 \%{ }^{*} 10^{-4} / \mathrm{n}$, respectively. In summary, bitumen and asphalt test results show subtle differences in the properties of both materials. It can be concluded that they show a very similar and comparable performance.

a)

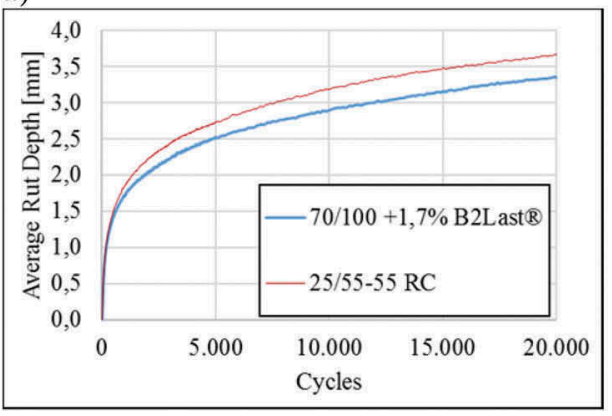

b)

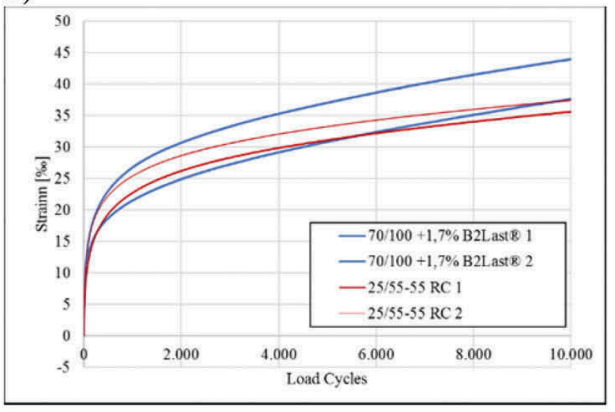

Figure 3. Results of wheel tracking and uniaxial cyclic compression tests.

\subsubsection{Low-temperature behavior}

In the case of the low temperature behavior, small differences between both materials could be identified. The uniaxial tensile strength test at $-10^{\circ} \mathrm{C}$ (Table 3 ) shows that the reference material has a higher tensile strength, although a comparable elongation at break. The elastic network created by the isocyanate-based modified bitumen is mostly effective in the high temperature range. Depending on the base bitumen (mainly on the ratio of asphaltenes to maltenes), it can have a positive or negligible influence on the low temperature behavior. Laboratory experiments (not included in this publication) have shown that higher amounts of the additive are required when using softer binders like a 70/100.

The thermal stress restrained test (Figure 4) shows and inverted picture in comparison to the UTST. In this case, cryogenic stresses appear to build up at lower temperatures for the isocyanate-modified asphalt, which means that the material is less susceptible to thermal stresses. This effect is common for chemically modified bitumen. Nevertheless, the cracking temperatures are very similar. The chemical additive had a break temperature on average at $-28^{\circ}$ $\mathrm{C}$, while the reference material on average at $-27.1{ }^{\circ} \mathrm{C}$. In summary, the low temperature behavior of the B2Last ${ }^{\circledR}$ based material depends highly on the neat base binder used. In this case, as in the case of the rutting performance, it can be stated that both materials perform at the same level in the low temperature range. 
Table 3. Results of uniaxial tensile strength test at $-10^{\circ} \mathrm{C}$.

\begin{tabular}{lll}
\hline \multirow{2}{*}{ Sample } & Tensile Strength & Elongation at Break \\
\cline { 2 - 3 } & {$[\mathrm{MPa}]$} & {$[\% 0]$} \\
\hline $25 / 55-55 \mathrm{RC}$ & 4,459 & 4,464 \\
$70 / 100+1,7 \%$ B2Last $\mathbb{}{ }^{2}$ & 2,675 & 5,923 \\
\hline
\end{tabular}

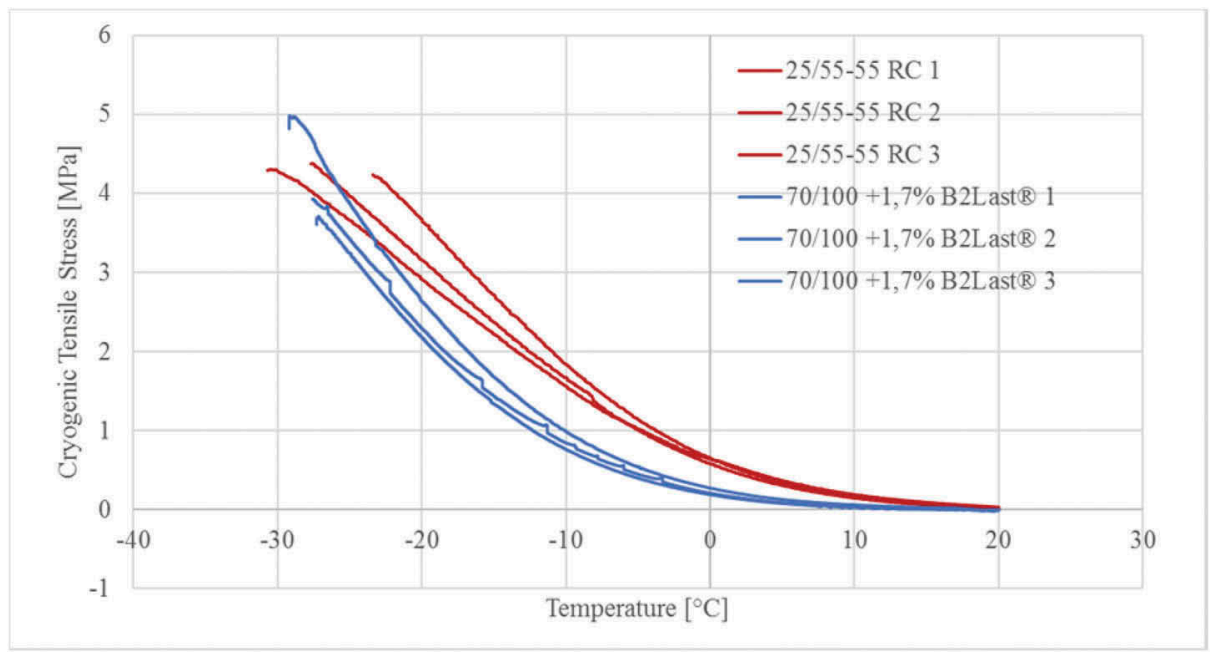

Figure 4. Thermal stress restrained specimen test results.

\subsection{Additional results}

In addition to the bitumen and asphalt tests, the construction of the test track with HMA provided key information about the possibilities that the B2Last ${ }^{\circledR}$ additive offers. During the construction of the test track, the material showed very good workability, considering it had $50 \%$ of reclaimed asphalt content. The compaction window was longer, and the odor was different to the SBS-modified asphalt. With these experience in mind, laboratory tests were performed to explore if the novel additive could allow asphalt production at lower temperatures, like for Warm Mix Asphalt processes, following the German Recommendations for Temperature Reduction of Asphalt (FGSV 2011). The results of this investigation lie outside the scope of this publication, since the results were submitted elsewhere, but the results showed that a temperature reduction was possible.

Since the construction of the test track presented here, two other paving trials have been successfully performed at on average $30{ }^{\circ} \mathrm{C}$ lower, still with high amounts of reclaimed asphalt and with the performance to the respective reference material (in both cases SBS modified asphalt mixtures). In both cases, the amount of the isocyanate-based additive was higher, between $2.0 \%$ and $2.5 \%$ by weight, referred to the total bitumen content (neat and reclaimed).

\section{CONCLUSIONS}

According to the analysis presented here, the following statements can be made: 
- The bitumen tests show that the polyurethane-precursor-modified bitumen has a similar rutting and low-temperature behavior compared to the PmB RC reference bitumen. By using a softer bitumen (like a neat PEN 70/100 bitumen), it is possible to cover a wide range of temperatures. Since the working principle of the novel additive is very different compared to classical elastomeric polymer modification, the elastomer-specific elastic recovery test is not applicable.

- The asphalt tests showed a comparable rutting and low-temperature behavior between both asphalt mixtures as well, confirming what was seen on a bitumen level. Additionally, the novel additive showed a lowering of the thermal susceptibility.

- The additive could be successfully blended in the mixing plant, without affecting production times nor temperatures. It allows an on-demand dosage and doesn't require any swelling time since it reacts quickly at addition to the bitumen and during mixing with aggregates (additive immobilization). During the paving process, the crosslinking of bitumen components by the additive is finalized and thus the modified asphalt achieves the elastic behavior it requires to endure traffic.

- The isocyanate-based additive showed an increase in the workability of the asphalt mixture during the first paving trial. This finding allowed to focus research in this direction and discover the ability of the modifier to produce high performing modified asphalt mixture at lower production and paving temperatures.

- The longitudinal and cross-section profiles of both reference and test track will be controlled every 6 months. Further analysis will be made with the data retrieved from these measurements.

The novel additive has the potential to be very helpful to the asphalt industry. It enables the production of modified asphalt mixtures on demand, without great technical requirements. Due to its nature, it works well with high amounts recycled materials, and, additionally, it allows the production of high performing warm-mix-asphalt mixtures.

\section{REFERENCES}

Alisov, Alexander; Riccardi, Chiara; Schrader, Johannes; Cannone Falchetto, Augusto; Wistuba, Michael P. (2020): A novel method to characterise asphalt binder at high temperature. In Road Materials and Pavement Design 21 (1), pp. 143-155. DOI: 10.1080/14680629.2018.1483258.

Bahia, H. U.; Anderson, D. A. (1995): The Development of the Bending Beam Rheometer; Basics and Critical Evaluation of the Rheometer. In J. C. Hardin (Ed.): Physical Properties of Asphalt Cement Binders. 100 Barr Harbor Drive, PO Box C700, West Conshohocken, PA 19428-2959: ASTM International, 28-28-23.

Carreño, Nicolás; Renken, Lukas; Schatz, Waldemar; Zeilinger, Michael; Bokern, Stefan; Fleischel, Olivier; Oeser, Markus (Eds.) (2020): New type of chemical modification of asphalt binders to enhance the performance of flexible. pavements Proceedings of the 7th Eurasphalt \& Eurobitume Congress v1.0. 7th Eurasphalt \& Eurobitume Congress. Madrid.

Cuadri, A. A.; García-Morales, M.; Navarro, F. J.; Partal, P. (2013): Isocyanate-functionalized castor oil as a novel bitumen modifier. In Chemical Engineering Science 97, pp. 320-327. DOI: 10.1016/j. ces.2013.04.045.

Cuadri, A. A.; Partal, P.; Ahmad, N.; Grenfell, J.; Airey, G. (2015): Chemically modified bitumens with enhanced rheology and adhesion properties to siliceous aggregates. In Construction and Building Materials 93, pp. 766-774. DOI: 10.1016/j.conbuildmat.2015.05.098.

D'Angelo, John A. (2009): The Relationship of the MSCR Test to Rutting. In Road Materials and Pavement Design 10 (sup1), pp. 61-80. DOI: 10.1080/14680629.2009.9690236.

FGSV (2011): Merkblatt für Temperaturabsenkung von Asphalt. M TA. Ausg. 2011. Köln (FGSV R2 Regelwerke, FGSV 766).

Karcher, Carsten (Ed.) (2012): Evaluation of the Deformation Resistance of Asphalt Mixes By Cyclic Compression Tests. E\&E 2012 Conference Paper.

Krishna Swamy, Aravind; Mitchell, Luke F.; Hall, Steven J.; Sias Daniel, Jo (2011): Impact of RAP on the Volumetric, Stiffness, Strength, and Low-Temperature Properties of HMA. In J. Mater. Civ. Eng. 23 (11), pp. 1490-1497. DOI: 10.1061/(ASCE)MT.1943-5533.0000245. 
Lesueur, Didier (2009): The colloidal structure of bitumen: consequences on the rheology and on the mechanisms of bitumen modification. In Advances in colloid and interface science 145 (1-2), pp. 42-82. DOI: $10.1016 /$ j.cis.2008.08.011.

Navarro, F. J.; Partal, P.; Martínez-Boza, F.; Gallegos, C.; Bordado, J. C. M.; Diogo, A. C. (2007): Rheology and microstructure of MDI-PEG reactive prepolymer-modified bitumen. In Mech Time-Depend Mater 10 (4), pp. 347-359. DOI: 10.1007/s11043-007-9029-2.

Radhakrishnan, Vishnu; Chowdari, G. Surendra; Reddy, K. Sudhakar; Chattaraj, Rajib (2019): Evaluation of wheel tracking and field rutting susceptibility of dense bituminous mixes. In Road Materials and Pavement Design 20 (1), pp. 90-109. DOI: 10.1080/14680629.2017.1374998.

Zhang, Jun; Walubita, Lubinda F.; Faruk, Abu N.M.; Karki, Pravat; Simate, Geoffrey S. (2015): Use of the MSCR test to characterize the asphalt binder properties relative to HMA rutting performance A laboratory study. In Construction and Building Materials 94, pp. 218-227. DOI: 10.1016/j. conbuildmat.2015.06.044. 